\title{
РЕАБИЛИТАЦИОННАЯ ТЕРАПИЯ КОМОРБИДНЫХ БОЛЬНЫХ С ОПУХОЛЯМИ ЩИТОВИДНОЙ ЖЕЛЕЗЫ В УСЛОВИЯХ АМБУЛАТОРНОГО ПРИЕМА
}

\author{
1,2Комарова А.Н., ${ }^{2}$ Задонцева Н.С., ${ }^{2}$ Кандаурова М.В. \\ 'Западно-Сибирская дирекция здравоохранения ОАО «РЖД», Новосибирск \\ 2ФГБОУ ВО «Алтайский государственный медицинский университет», Барнаул
}

ЦЕЛЬ: определить влияние коморбидной патологии на качество жизни пациента и возможности проведения у данной категории специального противоопухолевого лечения супрессивными дозами тиреоидных гормонов и реабилитационной терапии осложнений.

МАТЕРИАЛЫ И МЕТОДЫ: в исследование был включен 81 пациент с различными формами опухолей щитовидной железы. Оценка сопутствующих заболеваний проводилась согласно индексам коморбидности, а также исходя из результатов инструментальных исследований.

РЕЗУЛЬТАТЫ: полное отсутствие сопутствующей патологии наблюдалось у 4,9\% больных. Наличие более 4 конкурентных заболеваний - у 12,3\%. Самой частой сопутствующей патологией была гипертоническая болезнь (72,8\%). На втором месте - дисциркуляторная энцефалопатия - 66,7\%, на третьем месте - ишемическая болезнь сердца - 25,9\%. На четвертом - сахарный диабет - 23,4\%. В 3,7\% случаев декомпенсированная сопутствующая патология послужила поводом для отказа от проведения специального лечения.

У $82 \%$ пациентов на фоне проводимой супрессивной терапии отмечались различные кардиоваскулярные проявления. При этом преобладала кардиотоксичность 1-й степени, выявленная в 62,1\% случаев. Отмечены различные ее проявления: блокады пучка Гиса, экстрасистолии, метаболические изменения в миокарде. У всех пациентов фракция выброса левого желудочка сохранялась в целевых значениях выше 50\%, со снижением не более 5\% на фоне приема тиреоидных препаратов. В данной группе осуществлялось динамическое наблюдение врача-кардиолога с коррекцией возникших нарушений. Снижения дозы не потребовалось.

У 10,6\% пациентов наблюдались признаки кардиотоксичности 2-й степени, проявляющиеся снижением фракции выброса левого желудочка ниже 54\% или более чем на 10\% исходной, гипертоническими кризами, ишемическими изменениями в миокарде. Все пациенты получали лечение у врача-кардиолога. В 3 случаях $(4,5 \%)$ отмечено развитие фибрилляции предсердий, потребовавшее стационарного лечения. После коррекции кардиальной патологии все пациенты продолжают прием супрессивной дозы тироксина.

ВЫВОдЫ: при планировании терапии супрессивными дозами тироксина особое внимание необходимо уделять наличию коморбидной патологии, своевременная терапия которой может предотвратить развитие осложнений, особенно таких грозных, как кардиотоксичность. 